\title{
Clinical Trials of Combined Molecular Targeted Therapy and Locoregional Therapy in Hepatocellular Carcinoma: Past, Present, and Future
}

\author{
Hwi Young Kim ${ }^{\mathrm{a}}$ Joong-Won Park ${ }^{\mathrm{b}}$ \\ ${ }^{a}$ Department of Internal Medicine, Seoul National University Boramae Medical Center, Seoul, \\ ${ }^{b}$ Center for Liver Cancer, National Cancer Center, Gyeonggi-do, Republic of Korea
}

\section{Key Words}

Clinical trial · Combination · Hepatocellular carcinoma · Locoregional therapy ·

Molecular targeted therapy

\begin{abstract}
Background: Sorafenib, a multikinase inhibitor that targets angiogenesis in hepatocellular carcinoma ( $\mathrm{HCC})$, has become a standard treatment for advanced-stage HCC and has shown survival benefits in recent clinical trials. Transarterial chemoembolization (TACE) and sorafenib are currently standard treatments for intermediate and advanced-stage HCC, respectively. Combined locoregional therapy, including TACE and molecular targeted therapies such as sorafenib, is an issue under active investigation in an attempt to improve the outcomes of patients with unresectable HCC. Summary: Various clinical trials of these combined strategies have been conducted; however, the designs of these studies are diverse in terms of treatment modalities and schedules; comparisons with controls, baseline tumor stages, and hepatic functional reserves; and outcome measures. Key Messages: This article reviews heterogeneity in the design of recent clinical trials of combined locoregional and molecular targeted therapies and briefly addresses future study directions. Copyright $\odot 2014$ S. Karger AG, Basel
\end{abstract}




\section{Background}

Hepatocellular carcinoma (HCC), the sixth most commonly occurring cancer, is ranked as the third leading cause of cancer death worldwide [1, 2]. Because a considerable number of patients are diagnosed with advanced disease, only approximately one-third of HCC patients are eligible for potentially curative treatments such as resection, transplantation [3], or percutaneous ablation [4-7]. Transarterial chemoembolization (TACE) has been proven to provide survival benefits in subsets of patients with unresectable HCC and has thus become the standard therapy for patients with intermediate-stage HCC, which comprises multinodular tumors without vascular invasion or extrahepatic spread and preserved liver function in the absence of tumor-related symptoms [8-11]. However, TACE is considered a palliative treatment modality because complete tumor necrosis is rarely achieved, even with repeated treatments $[12,13]$. Additionally, TACE can potentially cause hypoxic changes in tumors as well as in the surrounding liver tissue from the anti-cancer effects of the infused chemotherapeutic agents and embolization of feeding arteries. Ischemic injuries resulting from TACE can induce the upregulation of circulating vascular endothelial growth factor (VEGF), which is important in HCC pathogenesis [14]. Recent studies have reported a significant association between VEGF upregulation after TACE and poor prognosis $[15,16]$. Therefore, efforts have been made to improve the outcomes of TACE with the adjuvant or concurrent use of an antiangiogenic agent. A representative example is sorafenib, which was the first systemic agent to provide survival benefits to patients with advanced HCC $[17,18]$. Sorafenib is a small molecule tyrosine kinase inhibitor that targets VEGF receptors, Raf kinase, and platelet-derived growth factor receptor-b [19]. Current research trends with respect to combined TACE and systemic antiangiogenic therapy for unresectable HCC were recently and comprehensively reviewed [20,21]. Consequently, this article covers the following two topics on clinical trial design from a critical viewpoint: (1) a brief review with updates of recent clinical trials that focused on synergistic efficacy by combining intra-arterial locoregional therapy (LRT) and molecular targeted agents (MTAs) with antiangiogenic properties and (2) future perspectives on combined LRT and MTA strategies. For the second topic, two different trial designs of LRT-MTA combinations were addressed in terms of their specific purposes: first, an attempt to overcome refractory responses to repeated TACE, and second, the additive efficacy of TACE to sorafenib in advanced-stage disease.

\section{Heterogeneous Designs of Recent Clinical Trials That Combined LRT and MTA in Patients with Unresectable HCC}

According to the recent European Association for the Study of the Liver (EASL) and the European Organisation for Research and Treatment of Cancer (EORTC) guidelines, which use the Barcelona Clinic Liver Cancer (BCLC) staging system, TACE is the current standard of care for patients with intermediate-stage HCC who present with multinodular tumors without evidence of macrovascular invasion or extrahepatic spread and have preserved hepatic functional reserve in the absence of cancer-related symptoms [10]. Procedures of the "conventional" TACE involves: i) superselective catheterization of the tumor feeding vessel(s); ii) intra-arterial infusion of chemotherapeutic agents such as doxorubicin, cisplatin, or various combinations of these agents either with or without a viscous emulsion; iii) tumor feeder artery embolization with gelatin sponge particles or other embolic agents [22].

However, TACE is considered a non-curative treatment because complete tumor necrosis is difficult to achieve, even with repeated TACE sessions [12]. In a meta-analysis by Llovet and Bruix, the objective response rate to TACE was 35\%, and the 2-year survival rate was 
$41 \%$ [23]. In a recent pathologic analysis, complete necrosis was observed in only $43 \%$ of 122 HCC nodules [24]. Thus, a high rate of tumor recurrence after TACE is predictable, and this fact explains the finding that $67 \%$ of post-TACE deaths in a randomized study were caused by tumor progression [8]. In addition to incomplete necrosis, TACE can potentially cause hypoxia in tumor tissues as well as in the surrounding liver parenchyma from the anti-cancer effects of chemotherapy and embolization of the tumor feeding arteries. Ischemic injury after TACE can induce the upregulation of circulating VEGF [14], which is essential for HCC growth, invasion, and metastasis. VEGF levels are known to correlate with tumor size, tumor number, vascular invasion, and poor survival in HCC patients [25]. Recent studies have reported that poor prognosis, particularly a higher risk of extrahepatic metastases and reduced progression-free survival, was associated with post-TACE upregulation of VEGF $[15,16]$. Based on these concepts, the adjuvant or concurrent use of an antiangiogenic agent, with the intent of complementary inhibition of both angiogenic factors and tumor growth, has been attempted in patients with unresectable HCC for whom TACE was indicated [26].

To date, there have been more than 20 clinical trials of combined LRT and MTA. In the majority of these trials, the treatment modalities were TACE and sorafenib. Because in-depth reviews of these trials were recently reported elsewhere $[20,21]$, this section focuses on the designs of these recent studies, especially those that were published as original articles. Studies that met the following criteria were excluded from further consideration: single-arm studies of which the results were only (partially) available as abstracts at the time of preparation of this review, studies with low numbers of subjects $(<20)$, or (retrospective) studies of observational design. Table 1 summarizes the designs of recent key clinical trials of combined LRT and MTA [27-35]. The study designs varied widely; for example, there were comparative vs. non-comparative designs, conventional TACE vs. more sophisticated types of intraarterial therapy, and various MTA administration timings and primary endpoints. The most noteworthy feature among these studies was the heterogeneous disease statuses of the study populations in terms of both tumor stages and baseline liver function. This heterogeneity was probably inevitable because initial trials, including the study by Kudo et al., began as early as 2006 [27]. Sorafenib was approved as the standard-of-care for patients with advancedstage, or BCLC stage C, HCC in 2008 after the results of the landmark Sorafenib Hepatocellular Carcinoma Assessment Randomized Protocol (SHARP) trial were reported [17]. Later, major evidence-based treatment guidelines endorsed sorafenib as the foundation for treating advanced-stage HCC $[10,13,36]$, and recommendations for prospective trial designs according to the BCLC staging system-based treatment guidelines were recently proposed [10]. The recommended trial designs indicated that the current standard treatment should be used as a control arm in a patient population with a specific BCLC stage, with TACE and sorafenib used for BCLC stage B and stage C patients, respectively. Before establishing this BCLC stage-oriented study design, the abovementioned trials that combined LRT and MTA enrolled patients with "unresectable" HCC, a condition that was not clearly defined and which thus allowed intermingled populations of BCLC stage B and C patients in a single trial. Again, it appeared inevitable that studies designed before the results of the SHARP or Asia-Pacific trials became available would adopt vague inclusion criteria such as "unresectable" HCC [17, 18]. Additionally, patient selection should be limited to those in Child-Pugh class A to derive the benefit of a newly attempted therapy by minimizing type II errors and avoiding competitive risk of death resulting from underlying cirrhosis-related liver failure. The importance of the ChildPugh class on sorafenib therapy outcomes was recently reported in several papers [37-39]. A retrospective cohort study from Korea reported heterogeneous outcomes for patients treated with sorafenib according to their Child-Pugh score subgroups, and the presence of ascites was a significant prognostic factor in Child-Pugh class B patients [39]. 


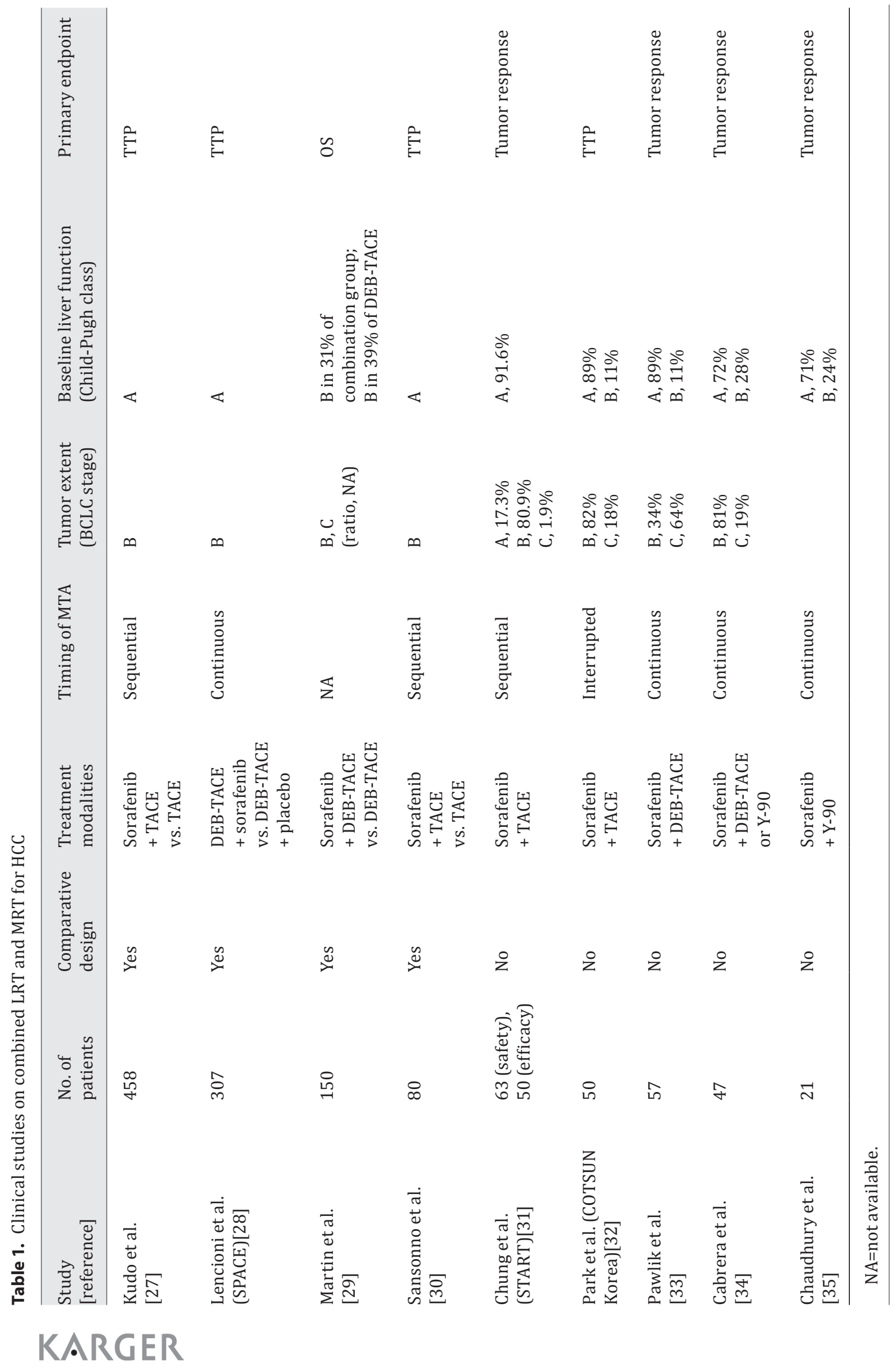


Although more than 20 clinical trials of LRT-MTA combinations have been completed or are in progress, and some have demonstrated promising results, several essential questions remain unanswered. Previously recognized unresolved issues [20,21] include the safety and efficacy of combined therapies in Child-Pugh class B or C patients, the optimal timing of MTA relative to LRT, the most beneficial type of LRT for combined therapy, the proper methods for radiological evaluations, and validated serum biomarkers. Moreover, we hereby suggest the following more fundamental questions concerning trial design: to whom, and when, should the LRT-MTA combination be applied to achieve the maximum benefit? To answer the first question on the basis of current standard HCC management, a randomized controlled trial of LRT alone vs. LRT plus MTA in Child-Pugh class A patients with intermediate-stage HCC is required. "Unresectable" HCC is a vague term that encompasses a wide range of conditions with respect to tumor stage and degree of liver function. Because surgical resection, local ablation, or transplantation is indicated for BCLC stage 0 (very early stage) or stage A (early stage) disease with a relatively good prognosis, and because sorafenib is currently the only treatment option for advanced-stage, or BCLC stage C disease, the LRT-MTA combination appears attractive for patients with intermediate-stage, or BCLC stage B disease, especially given the complementary properties of antiangiogenic MTA and TACE mentioned earlier. However, given the natural course of intermediate-stage HCC, we require more data regarding the duration of sorafenib maintenance in LRT-MTA combination treatment. A recent report noted that prolonged sorafenib use could cause irreversible pancreatic atrophy [40].

Among the various LRT methods, including conventional TACE, TACE with drug-eluting beads (DEB-TACE), and radioembolization, conventional TACE could be the appropriate LRT modality. Although DEB-TACE has shown less toxicity and similar outcomes compared with conventional TACE, it has not demonstrated a definite superiority to conventional TACE in terms of overall survival (OS) [41]. Despite promising results, it is not known whether radioembolization confers more benefits than conventional TACE or DEB-TACE [42, 43]. The selection of a proper MTA for combined therapy appears less controversial than the choice of LRT modality because sorafenib is currently the only approved MTA for HCC and has proven efficacy in advanced-stage HCC. Considering the second question, the timing of MTA administration is another difficult issue. Among the three previously proposed combination regimens, i.e., sequential, interrupted, and continuous schedules, the latter two suggest administering the combination from the beginning of treatment [26]. However, patients with intermediatestage HCC are known to have a median survival duration of up to 20 months when treated with TACE [10]. If a patient responds well to TACE and achieves a complete response after one or two sessions, the additive survival benefit of combined MTA administered from the beginning of treatment might be difficult to detect. The synergistic effectiveness of the TACE-MTA combination when administered throughout treatment in intermediate-stage patients was not consistently established in recent clinical trials because of the heterogeneity in the trial designs. A more desirable LRT-MTA combination schedule would focus on improving the outcomes of patients who respond poorly to TACE. From this point of view, the concept of "TACE refractoriness" has been suggested $[44,45]$, and a combination strategy for TACE refractoriness is addressed in the next section.

\section{Future Directions for LRT-MTA Combination Strategies}

\section{To Overcome TACE Refractoriness in Intermediate-Stage HCC}

Recent EASL-EORTC guidelines recommend switching to sorafenib if non-responsiveness to at least two cycles of TACE is observed in intermediate-stage HCC patients [10]. This recom- 
mendation is referred to as "treatment stage migration," based on the results of the SHARP trial [17]. However, the SHARP trial did not aim to investigate the efficacy of sorafenib in uniformly TACE-refractory patients. The appropriate strategy for TACE-refractory patients has not yet been fully investigated. Moreover, the definition of "TACE refractoriness" has not been established. A recent cohort study of 264 TACE-treated patients suggested that disease progression during the first 6 months from the initial TACE treatment or a requirement for three sessions of repeated TACE within the first 6 months might be considered criteria for TACE refractoriness [46]. Because TACE refractoriness is an ill-defined concept, further investigations are urgently warranted to define and overcome this phenomenon in the near future and to verify whether a combined approach of TACE and MTA might be an effective therapeutic option for TACE refractoriness.

To Improve the Outcomes of Patients with Advanced-Stage HCC by Adding LRT to Sorafenib

There are limited data regarding the efficacy of TACE for advanced-stage HCC. TACE has been contraindicated in HCC patients with portal venous invasion or extrahepatic spread [44] because of concerns of hepatic decompensation following TACE in the former and a lack of sufficient data in the latter. However, recent reports suggested that TACE can be safely performed and may confer survival benefits to carefully selected advanced-stage HCC patients with vascular invasion and/or extrahepatic metastases [47-52]. Some experts have advocated the addition of TACE to treatment guidelines for cases of portal venous invasion if the first-order branch from the main portal vein is not involved [45]. With this background, a randomized, controlled, multi-center, open-label phase III study in patients with advancedstage HCC was recently initiated in Korea (STAH trial, NCT01829035). A total of 338 patients were randomized (1:1) to either combined sorafenib with conventional TACE therapy or sorafenib monotherapy. TACE will be repeated on an on-demand basis. The primary outcome is OS, and the secondary outcome variables include the time to progression (TTP), tumor response rate, progression-free survival, and safety. Notably, the inclusion criteria comprise advanced-stage HCC and TACE-refractory HCC, which was defined as either disease progression or the requirement for three sessions of repeated TACE within the first 6 months after the initial TACE treatment, as described earlier [46].

\section{Conclusion}

Treatment strategies continue to evolve to achieve better survival in HCC patients. As part of this effort, combined treatment strategies, particularly the combination of LRT with MTA, have become an active topic of investigation in the field of HCC treatment. A representative example, i.e., combined TACE and sorafenib, has produced promising results in recent clinical trials. However, the study designs of those trials were highly variable in terms of the treatment schedules, comparisons with controls, the baseline tumor characteristics and hepatic function of the study subjects, and outcome variables. In addition to verifying the synergistic effect, future trials should address whether combinations with MTA can overcome TACE refractoriness in intermediate-stage HCC patients and whether TACE might have an additive role when combined with sorafenib for advanced-stage HCC treatment. Recently initiated clinical trials are expected to provide answers to these questions. 


\section{References}

1 Jemal A, Siegel R, Ward E, Hao Y, Xu J, Murray T, Thun MJ: Cancer statistics, 2008. CA Cancer J Clin 2008;58:71-96.

-2 Ferlay J, Shin HR, Bray F, Forman D, Mathers C, Parkin DM: Estimates of worldwide burden of cancer in 2008: GLOBOCAN 2008. Int J Cancer 2010;127:2893-2917.

3 Belghiti J, Fuks D: Liver resection and transplantation in hepatocellular carcinoma. Liver Cancer 2012;1:71-82.

4 Bruix J, Llovet JM: Prognostic prediction and treatment strategy in hepatocellular carcinoma. Hepatology 2002;35:519-524.

5 Park KW, Park JW, Choi JI, Kim TH, Kim SH, Park HS, Lee WJ, Park SJ, Hong EK, Kim CM: Survival analysis of 904 patients with hepatocellular carcinoma in a hepatitis B virus-endemic area. J Gastroenterol Hepatol 2008;23:467-473.

6 Lin SM: Local ablation for hepatocellular carcinoma in Taiwan. Liver Cancer 2013;2:73-83.

7 Lin S, Hoffmann K, Schemmer P: Treatment of hepatocellular carcinoma: a systematic review. Liver Cancer 2012;1:144-158.

8 Llovet JM, Real MI, Montaña X, Planas R, Coll S, Aponte J, Ayuso C, Sala M, Muchart J, Solà R, Rodés J, Bruix J, Barcelona Liver Cancer Group: Arterial embolisation or chemoembolisation versus symptomatic treatment in patients with unresectable hepatocellular carcinoma: a randomised controlled trial. Lancet 2002;359:1734-1739.

-9 Lo CM, Ngan H, Tso WK, Liu CL, Lam CM, Poon RT, Fan ST, Wong J: Randomized controlled trial of transarterial lipiodol chemoembolization for unresectable hepatocellular carcinoma. Hepatology 2002;35:11641171.

10 European Association For The Study Of The Liver European Organisation For Research And Treatment Of Cancer: EASL-EORTC clinical practice guidelines: management of hepatocellular carcinoma. J Hepatol 2012;56:908-943.

11 Lencioni R: Chemoembolization in patients with hepatocellular carcinoma. Liver Cancer 2012;1:41-50.

12 Alba E, Valls C, Dominguez J, Martinez L, Escalante E, Lladó L, Serrano T: Transcatheter arterial chemoembolization in patients with hepatocellular carcinoma on the waiting list for orthotopic liver transplantation. AJR Am J Roentgenol 2008;190:1341-1348.

13 Bruix J, Sherman M, American Association for the Study of Liver Diseases: Management of hepatocellular carcinoma: an update. Hepatology 2011;53:1020-1022.

14 Li X, Feng GS, Zheng CS, Zhuo CK, Liu X: Expression of plasma vascular endothelial growth factor in patients with hepatocellular carcinoma and effect of transcatheter arterial chemoembolization therapy on plasma vascular endothelial growth factor level. World J Gastroenterol 2004;10:2878-2882.

15 Shim JH, Park JW, Kim JH, An M, Kong SY, Nam BH, Choi JI, Kim HB, Lee WJ, Kim CM: Association between increment of serum VEGF level and prognosis after transcatheter arterial chemoembolization in hepatocellular carcinoma patients. Cancer Sci 2008;99:2037-2044.

16 Sergio A, Cristofori C, Cardin R, Pivetta G, Ragazzi R, Baldan A, Girardi L, Cillo U, Burra P, Giacomin A, Farinati F: Transcatheter arterial chemoembolization (TACE) in hepatocellular carcinoma (HCC): the role of angiogenesis and invasiveness. Am J Gastroenterol 2008;103:914-921.

-17 Llovet JM, Ricci S, Mazzaferro V, Hilgard P, Gane E, Blanc JF, de Oliveira AC, Santoro A, Raoul JL, Forner A, Schwartz M, Porta C, Zeuzem S, Bolondi L, Greten TF, Galle PR, Seitz JF, Borbath I, Häussinger D, Giannaris T, Shan M, Moscovici M, Voliotis D, Bruix J, SHARP Investigators Study Group: Sorafenib in advanced hepatocellular carcinoma. N Engl J Med 2008;359:378-390.

18 Cheng AL, Kang YK, Chen Z, Tsao CJ, Qin S, Kim JS, Luo R, Feng J, Ye S, Yang TS, Xu J, Sun Y, Liang H, Liu J, Wang J, Tak WY, Pan H, Burock K, Zou J, Voliotis D, Guan Z: Efficacy and safety of sorafenib in patients in the Asia-Pacific region with advanced hepatocellular carcinoma: a phase III randomised, double-blind, placebo-controlled trial. Lancet Oncol 2009;10:25-34.

-19 Wilhelm SM, Carter C, Tang L, Wilkie D, McNabola A, Rong H, Chen C, Zhang X, Vincent P, McHugh M, Cao Y, Shujath J, Gawlak S, Eveleigh D, Rowley B, Liu L, Adnane L, Lynch M, Auclair D, Taylor I, Gedrich R, Voznesensky A, Riedl B, Post LE, Bollag G, Trail PA: BAY 43-9006 exhibits broad spectrum oral antitumor activity and targets the RAF/MEK/ERK pathway and receptor tyrosine kinases involved in tumor progression and angiogenesis. Cancer Res 2004;64:7099-7109.

20 Liapi E, Geschwind JF: Combination of local transcatheter arterial chemoembolization and systemic antiangiogenic therapy for unresectable hepatocellular carcinoma. Liver Cancer 2012;1:201-215.

-21 Weintraub JL, Salem R: Treatment of hepatocellular carcinoma combining sorafenib and transarterial locoregional therapy: state of the science. J Vasc Interv Radiol 2013;24:1123-1134.

22 Meza-Junco J, Montano-Loza AJ, Liu DM, Sawyer MB, Bain VG, Ma M, Owen R: Locoregional radiological treatment for hepatocellular carcinoma; Which, when and how? Cancer Treat Rev 2012;38:54-62.

23 Llovet JM, Bruix J: Systematic review of randomized trials for unresectable hepatocellular carcinoma: Chemoembolization improves survival. Hepatology 2003;37:429-442.

24 Golfieri R, Cappelli A, Cucchetti A, Piscaglia F, Carpenzano M, Peri E, Ravaioli M, D’Errico-Grigioni A, Pinna $\mathrm{AD}$, Bolondi L: Efficacy of selective transarterial chemoembolization in inducing tumor necrosis in small $(<5 \mathrm{~cm})$ hepatocellular carcinomas. Hepatology 2011;53:1580-1589.

25 Schoenleber SJ, Kurtz DM, Talwalkar JA, Roberts LR, Gores GJ: Prognostic role of vascular endothelial growth factor in hepatocellular carcinoma: systematic review and meta-analysis. Br J Cancer 2009;100:1385-1392.

26 Strebel BM, Dufour JF: Combined approach to hepatocellular carcinoma: a new treatment concept for nonresectable disease. Expert Rev Anticancer Ther 2008;8:1743-1749. 
27 Kudo M, Imanaka K, Chida N, Nakachi K, Tak WY, Takayama T, Yoon JH, Hori T, Kumada H, Hayashi N, Kaneko S, Tsubouchi H, Suh DJ, Furuse J, Okusaka T, Tanaka K, Matsui O, Wada M, Yamaguchi I, Ohya T, Meinhardt G, Okita K: Phase III study of sorafenib after transarterial chemoembolisation in Japanese and Korean patients with unresectable hepatocellular carcinoma. Eur J Cancer 2011;47:2117-2127.

28 Lencioni R, Zou J, Leberre M, Meinhardt G, Voliotis D, Bruix J, Llovet J: Sorafenib (SOR) or placebo (PL) in combination with transarterial chemoembolization (TACE) for intermediate-stage hepatocellular carcinoma (SPACE). J Clin Oncol 2010;28:178.

29 Martin RC, Keck G, Robbins K, Strnad B, Dubel G, Longares J, Padr R, Narayanan G: Evaluation of sorafenib in combination with doxorubicin-loaded DC bead as a combination treatment option for HCC. ASCO Gastrointestinal Cancers Symposium 2010;Abstract 216.

- 30 Sansonno D, Lauletta G, Russi S, Conteduca V, Sansonno L, Dammacco F: Transarterial chemoembolization plus sorafenib: a sequential therapeutic scheme for HCV-related intermediate-stage hepatocellular carcinoma: a randomized clinical trial. Oncologist 2012;17:359-366.

-31 Chung YH, Han G, Yoon JH, Yang J, Wang J, Shao GL, Kim BI, Lee TY, Chao Y: Interim analysis of START: Study in Asia of the combination of TACE (transcatheter arterial chemoembolization) with sorafenib in patients with hepatocellular carcinoma trial. Int J Cancer 2013;132:2448-2458.

32 Park JW, Koh YH, Kim HB, Kim HY, An S, Choi JI, Woo SM, Nam BH: Phase II study of concurrent transarterial chemoembolization and sorafenib in patients with unresectable hepatocellular carcinoma. J Hepatol 2012;56:1336-1342.

-33 Pawlik TM, Reyes DK, Cosgrove D, Kamel IR, Bhagat N, Geschwind JF: Phase II trial of sorafenib combined with concurrent transarterial chemoembolization with drug-eluting beads for hepatocellular carcinoma. J Clin Oncol 2011;29:3960-3967.

-34 Cabrera R, Pannu DS, Caridi J, Firpi RJ, Soldevila-Pico C, Morelli G, Clark V, Suman A, George TJ Jr, Nelson DR: The combination of sorafenib with transarterial chemoembolisation for hepatocellular carcinoma. Aliment Pharmacol Ther 2011;34:205-213.

35 Chaudhury P, Hassanain M, Nudo C, Bouteaud J, Cabrera T, Valenti D, Metrakos P: Combined sorafenib and yttrium-90 radio-embolization in the treatment of advanced HCC: preliminary results. Hepatology 2009; 50(S4): Abstract 1786.

36 Benson AB 3rd, Abrams TA, Ben-Josef E, Bloomston PM, Botha JF, Clary BM, Covey A, Curley SA, D'Angelica MI, Davila R, Ensminger WD, Gibbs JF, Laheru D, Malafa MP, Marrero J, Meranze SG, Mulvihill SJ, Park JO, Posey JA, Sachdev J, Salem R, Sigurdson ER, Sofocleous C, Vauthey JN, Venook AP, Goff LW, Yen Y, Zhu AX: NCCN clinical practice guidelines in oncology: hepatobiliary cancers. J Natl Compr Canc Netw 2009;7:350-391.

37 Kim JE, Ryoo BY, Ryu MH, Chang HM, Suh DJ, Lee HC, Lim YS, Kim KM, Kang YK: Sorafenib for hepatocellular carcinoma according to Child-Pugh class of liver function. Cancer Chemother Pharmacol 2011;68:1285-1290.

- 38 Chiu J, Tang YF, Yao TJ, Wong A, Wong H, Leung R, Chan P, Cheung TT, Chan AC, Pang R, Fan ST, Poon R, Yau $\mathrm{T}$ : The use of single-agent sorafenib in the treatment of advanced hepatocellular carcinoma patients with underlying Child-Pugh B liver cirrhosis: a retrospective analysis of efficacy, safety, and survival benefits. Cancer 2012;118:5293-5301.

-39 Kim HY, Park JW, Joo J, Kim H, Woo SM, Lee WJ, Kim CM: Worse outcome of sorafenib therapy associated with ascites and Child-Pugh score in advanced hepatocellular carcinoma. J Gastroenterol Hepatol 2013;28:1756-1761.

40 Hescot S, Vignaux O, Goldwasser F: Pancreatic atrophy - a new late toxic effect of sorafenib. N Engl J Med 2013;369:1475-1476.

- 41 Lencioni R, de Baere T, Burrel M, Caridi JG, Lammer J, Malagari K, Martin RC, O’Grady E, Real MI, Vogl TJ, Watkinson A, Geschwind JF: Transcatheter treatment of hepatocellular carcinoma with Doxorubicinloaded DC Bead (DEBDOX): technical recommendations. Cardiovasc Intervent Radiol 2012;35:980-985.

-42 Salem R, Lewandowski RJ, Mulcahy MF, Riaz A, Ryu RK, Ibrahim S, Atassi B, Baker T, Gates V, Miller FH, Sato KT, Wang E, Gupta R, Benson AB, Newman SB, Omary RA, Abecassis M, Kulik L: Radioembolization for hepatocellular carcinoma using yttrium-90 microspheres: a comprehensive report of long-term outcomes. Gastroenterology 2010;138:52-64.

-43 Salem R, Lewandowski RJ, Kulik L, Wang E, Riaz A, Ryu RK, Sato KT, et al: Radioembolization results in longer time-to-progression and reduced toxicity compared with chemoembolization in patients with hepatocellular carcinoma. Gastroenterology 2011;140:497-507 e492.

-44 Raoul JL, Sangro B, Forner A, Mazzaferro V, Piscaglia F, Bolondi L, Lencioni R: Evolving strategies for the management of intermediate-stage hepatocellular carcinoma: available evidence and expert opinion on the use of transarterial chemoembolization. Cancer Treat Rev 2011;37:212-220.

45 Yamashita T, Kaneko S: Treatment strategies for hepatocellular carcinoma in Japan. Hepatol Res 2013;43:44-50.

46 Kim HY, Park JW, Joo J, Jung SJ, An S, Woo SM, Kim HB, Koh YH, Lee WJ, Kim CM: Severity and timing of progression predict refractoriness to transarterial chemoembolization in hepatocellular carcinoma. J Gastroenterol Hepatol 2012;27:1051-1056.

-47 Pinter M, Hucke F, Graziadei I, Vogel W, Maieron A, Königsberg R, Stauber R, Grünberger B, Müller C, Kölblinger C, Peck-Radosavljevic M, Sieghart W: Advanced-stage hepatocellular carcinoma: transarterial chemoembolization versus sorafenib. Radiology 2012;263:590-599.

48 Chung GE, Lee JH, Kim HY, Hwang SY, Kim JS, Chung JW, Yoon JH, Lee HS, Kim YJ: Transarterial chemoembolization can be safely performed in patients with hepatocellular carcinoma invading the main portal vein and may improve the overall survival. Radiology 2011;258:627-634. 
Kim et al.: Trials of Combination Treatment in Hepatocellular Carcinoma

49 Kim KM, Kim JH, Park IS, Ko GY, Yoon HK, Sung KB, Lim YS, Lee HC, Chung YH, Lee YS, Suh DJ: Reappraisal of repeated transarterial chemoembolization in the treatment of hepatocellular carcinoma with portal vein invasion. J Gastroenterol Hepatol 2009;24:806-814.

50 Kim HY, Park JW, Nam BH, Kim HK, Choi JI, Kim TH, Kim HB, Kim CM: Survival of patients with advanced hepatocellular carcinoma: sorafenib versus other treatments. J Gastroenterol Hepatol 2011;26:1612-1618.

51 Yoo DJ, Kim KM, Jin YJ, Shim JH, Ko GY, Yoon HK, Sung KB, Lee JL, Kang YK, Lim YS, Lee HC, Chung YH, Lee YS, Suh DJ: Clinical outcome of 251 patients with extrahepatic metastasis at initial diagnosis of hepatocellular carcinoma: does transarterial chemoembolization improve survival in these patients? J Gastroenterol Hepatol 2011;26:145-154.

52 Kim JH, Yoon HK, Kim SY, Kim KM, Ko GY, Gwon DI, Sung KB: Transcatheter arterial chemoembolization vs. chemoinfusion for unresectable hepatocellular carcinoma in patients with major portal vein thrombosis. Aliment Pharmacol Ther 2009;29:1291-1298. 